\title{
Partial characterization of a togavirus (LOVV) associated with histopathological changes of the lymphoid organ of penaeid shrimps
}

\author{
J. R. Bonami ${ }^{1}$, D. V. Lightner ${ }^{2, *}$, R. M. Redman ${ }^{2}$, B. T. Poulos ${ }^{2}$ \\ ${ }^{1}$ Laboratoire de Pathologie Comparée, Université Montpellier, Sciences et Techniques du Languedoc, CP 104 Place Eugene \\ Bataillon, F-34095 Montpellier Cedex 5, France \\ ${ }^{2}$ Department of Veterinary Science, University of Arizona, Tucson, Arizona 85721, USA
}

\begin{abstract}
Histological and ultrastructural studies of abnormal lymphoid organs from a population of cultured Penaeus vannamei (Crustacea: Decapoda) revealed the presence of a previously unreported virus infecting this group of marine invertebrate animals. Named LOVV (lymphoid organ vacuolization virus), the virus was found in the cytoplasm of lymphoid organ cells which had a highly vacuolated cytoplasm and intracytoplasmic eosinophilic to pale basophilic, Feulgen negative, inclusion bodies. Many affected cells also possessed pyknotic or karyorrhectic nuclei. In some foci, affected lymphoid cells formed large multicellular spherical structures, termed spheroids, which lacked a central vessel. Icosahedral nucleocapsids averaging $30 \mathrm{~nm}$ in diameter were present in dense cytoplasmic aggregates, occasionally forming paracrystalline arrays, or as single rows of particles thatwere closely associated with host cell membranes where they acquired their host-membrane-derived envelope. Purified enveloped virions had a buoyant density of $1.23 \mathrm{~g} \mathrm{ml}^{-1}$ and a diameter of 52 to 54 $\mathrm{nm}$, while nucleocapsids were icosahedral in shape, 30 to $31 \mathrm{~nm}$ in diameter, and exhibited a buoyant density of $1.32 \mathrm{~g} \mathrm{ml}^{-1}$ Constitutive polypeptides had a molecular weight of $70,60,38$ and $37 \mathrm{kDa}$. Based on its size, structure, and virogenesis, LOVV is considered to be a member of the Togaviridae
\end{abstract}

\section{INTRODUCTION}

Histopathological changes of the lymphoid organ of penaeid shrimps have been recognized by different authors in different species. A condition has been reported in Penaeus monodon and certain other Penaeus spp. in which the lymphoid or 'Oka organ' displayed hyperplasia, formation of 'spheroids', and metastasis of detached 'spheroids' (Lightner \& Brock 1986, Lightner et al. 1987). The condition was considered as an idiopathic proliferative disease of the lymphoid organ (Brock \& Lightner 1990). Such lesions were observed also in $P$. monodon and $P$. penicillatus cultured in Taiwan (Lightner et al. 1987) and in $P$. esculentus in Australia (Paynter et al. 1985); they have also been found in $P$. vannamei, $P$. stylirostris, $P$. chinensis (Lightner \& Brock unpubl.) and $P$. merguiensis in Australia (Owens et al. 1991). Brock \& Lightner

\footnotetext{
- Addressee for correspondence
}

(1990) did not consider the lymphoid organ changes they studied to be associated with a specific disease syndrome, because abnormal lymphoid organs were found in apparently healthy shrimp as well as in ones that displayed clinical signs of other disease syndromes. In marked contrast were reports from Australia, where nearly identical lymphoid organ lesions were associated initially with a serious disease syndrome of adult $P$. merguiensis (Owens \& Hall-Mendelin 1988) and subsequently with a presumed parvo-like virus infection in cultured and wild $P$. monodon, $P$. esculentus and $P$. merguiensis (Owens et al. 1991).

Recent electron microscopic investigations of hypertrophied lymphoid organ cells have provided evidence of virus-like particles of 18 to $20 \mathrm{~nm}$ diameter in the nuclei of lymphoid organ (LO) cells in Australian penaeid shrimp (Owens et al. 1991) and 25 to $30 \mathrm{~nm}$ diameter in the cytoplasm of LO cells in Penaeus vannamei from North America (Lightner unpubl.). However, in both instances either purification attempts were not made or they were unsuccessful. 
We report here our results on the concentration, purification and partial characterization of a newly recognized virus that was found to be associated with lymphoid organ lesions in cultured Penaeus vannamei. For the purpose of this paper, we have named the virus LOVV, which is abbreviated from 'lymphoid organ vacuolization virus', to reflect the principal lesion found to be associated with the virus.

\section{MATERIALS AND METHODS}

Experimental animals. The shrimp used in this study were subadult (ca $15 \mathrm{~g}$ average weight and 21 mo of age) Penaeus vannamei which had been reared from postlarvae obtained in June 1989 from a commercial source in Mazatlan, Sinaloa, Mexico. The shrimp were reared in isolated self-contained $1500 \mathrm{l}$ tanks. Each tank was equipped with its own biological filter Artificial seawater in the tanks was circulated through a central stand pipe connected to a bottom drain line, which in turn was connected to a biological filter. Water was returned to the rearing tank by use of air-lift pipes. Salinity was maintained at approximately $20 \mathrm{ppt}$ by the addition of city water. Water temperature throughout the 21 mo growout period was maintained between 24 and $28^{\circ} \mathrm{C}$. Shrimp were fed twice daily with artificial pelleted shrimp feeds purchased from Rangen Feed Company (Buhl, ID, USA). Shrimp from this cultured population were preserved for histological and transmission electron microscope (TEM) study, or frozen at $-70^{\circ} \mathrm{C}$ for use in later studies.

Histopathology. Shrimp selected for histological study were preserved in Davidson's fixative (Humason 1979, Bell \& Lightner 1988). Fixation was accomplished by first injecting ca $0.5 \mathrm{ml}$ of fixative directly into the hepatopancreas and adjacent areas of the cephalothorax of each live shrimp sampled. Then the cephalothorax was excised at its junction with the first abdominal segment, the carapace was slit just lateral to the dorsal midline using dissecting scissors, and the intact cephalothorax was immersed in fixative. After $48 \mathrm{~h}$ in Davidson's fixative, preserved shrimp cephalothoraces were transferred to $50 \%$ ethanol, and then processed for routine histological examination using standard paraffin embedding procedures and hematoxylin and eosin staining methods (and other staining procedures as described in Bell \& Lightner 1988).

Electron microscopy. Specimens for electron microscopy were fixed live by injection into the hepatopancreas and adjacent tissues (using a $1 \mathrm{ml}$ tuberculin syringe) of cold (ca $4{ }^{\circ} \mathrm{C}$ ) $6 \%$ glutaraldehyde in $0.15 \mathrm{M}$ Millonig's phosphate buffer (Pease 1964) supplemented with $1 \%$ sodium chloride and $0.5 \%$ sucrose to achieve a fixative osmolarity of 700 to $750 \mathrm{mOsm}$. Subsequently, the abdomen was excised and the carapace was opened as described in the procedure for preserving shrimp with Davidson's fixative, and the shrimp were immersed whole in the same fixative. Specimens were stored in fixative at $4{ }^{\circ} \mathrm{C}$ until processed further. Lymphoid organs from the specimens were removed by dissection and postfixed in $1 \%$ osmium tetroxide (in the same buffer as used for the glutaraldehyde fixative), dehydrated through graded alcohol, and embedded in Spurr's resin (Ladd Research Inc., Burlington, VT, USA). Ca 1 mm thick sections were prepared from each tissue block using glass knives and stained with $1 \%$ toluidine blue (in $1 \%$ aqueous sodium borate) for ca $1 \mathrm{~min}$ at $60^{\circ} \mathrm{C}$. Blocks showing potential lesions were then thin sectioned using a diamond knife on a Sorvall MT-2B ultramicrotome. Sections mounted on 200 mesh copper grids were stained with uranyl acetate and lead citrate and viewed in either an Hitachi HU-12 or H-500 electron microscope operating at $75 \mathrm{kV}$.

Virus purification. Frozen shrimp which had been stored at $-70^{\circ} \mathrm{C}$ were used as the source of virus.

Fig. 1 to 6. Penaeus vannamei infected by LOVV Fig. 1. Histological section of the lymphoid organ (LO) of a subadult shrimp displaying some essentially normal (N) areas and focal lesions. Normal areas consist of cords of LO parenchymal cells which surround a prominent central hemolymph vessel $(\mathrm{H})$. Areas with lesions lack a central vessel, and consist of cells which show

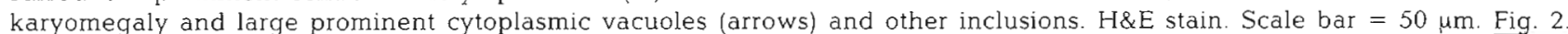
Higher magnification of a normal LO cord with its central hemolymph vessel (H) and surrounding sheath cells (S). Adjacent to it are areas of LO cells which lack a central vessel and which possess cells with prominent cytoplasmic vacuoles (V) and cytoplasmic inclusions that range from Feulgen negative, eosinophilic, and poorly defined to discrete basophilic Feulgen positive granules (G). Many affected cells are shown with slightly hypertrophied nuclei that possess marginated nuclear chromatin, leaving the nucleolus within the central portion of an otherwise hypochramatic nucleus. H\&E stain. Scale bar $=40 \mu m$. Fig. 3. Spheroids (S), or spherical masses of LO cells that lack a central vessel, form within focal LO lesions. Two are shown near a normal LO cord with its central hemolymph vessel $(\mathrm{H})$. Spheroids may contain foci of cells with hypertrophied nuclei and highly vacuolated cytoplasm (arrows). H\&E stain. Scale bar $=50 \mu \mathrm{m}$. Fig. 4. Spheroids (S) detached from the somal LO are shown in the hemocoel space between the LO and a tubule of the antennal gland (AG). H\&E stain. Scale bar $=40 \mu \mathrm{m}$. Fig. 5. TEM of an unorganized mass of 30 nm diameter LOVV nucleocapsids. The tendency of the particles to associate with host cell membranes is somewhat evident (arrows). Scale bar $=200 \mathrm{~nm}$. Fig. 6. TEM of a cytoplasmic mass of LOVV nucleocapsids which are closely associated with membranes (arrows) of host cell organelles. Scale bar $=200 \mathrm{~nm}$ 


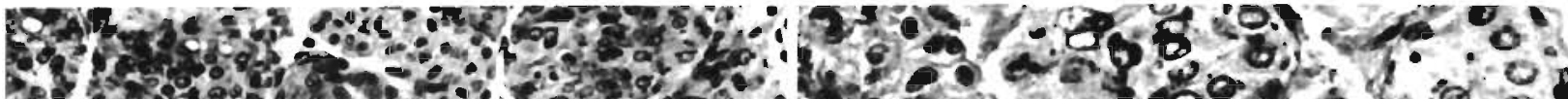

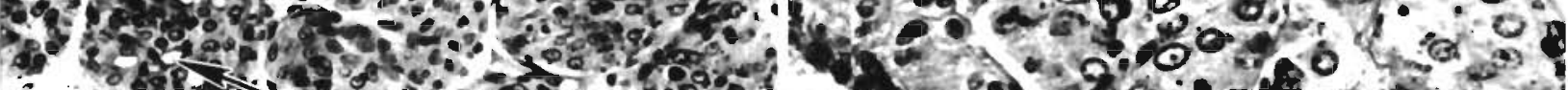

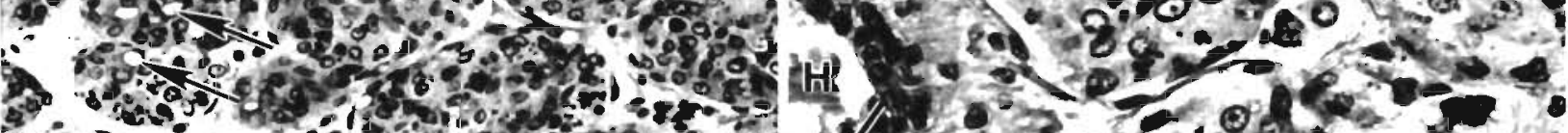

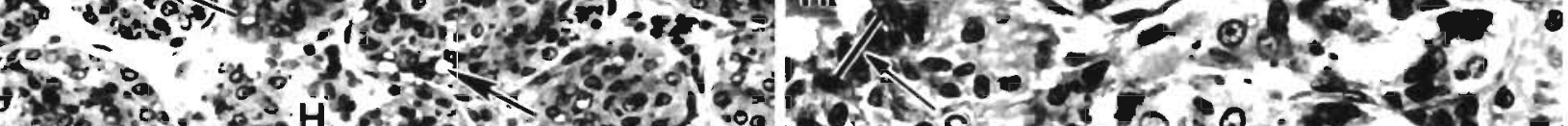

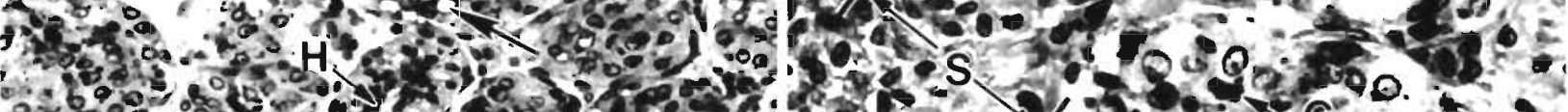

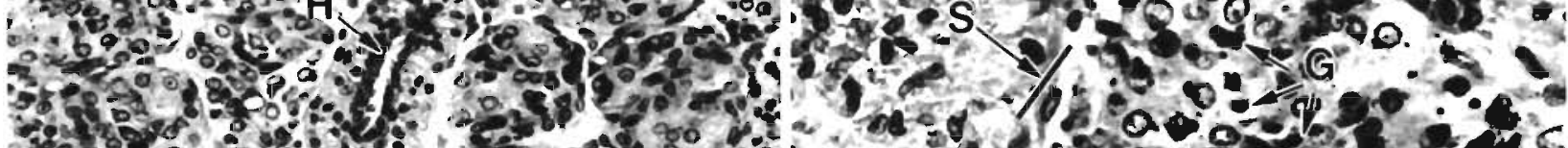

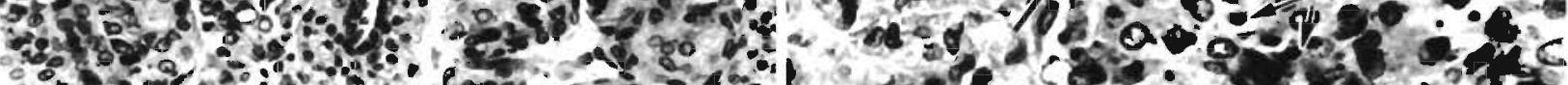

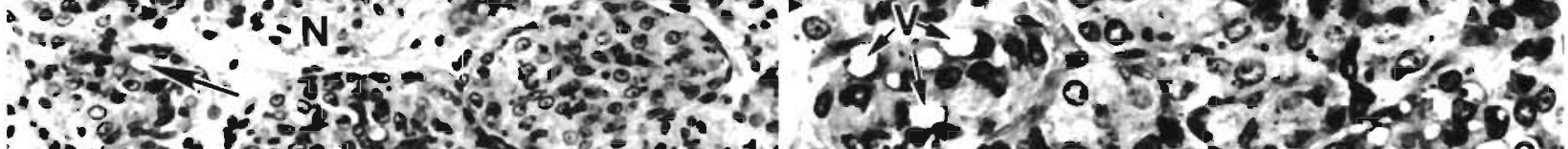

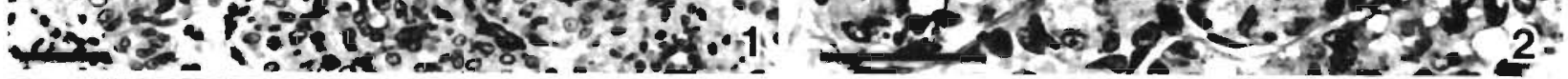

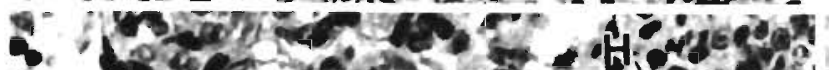

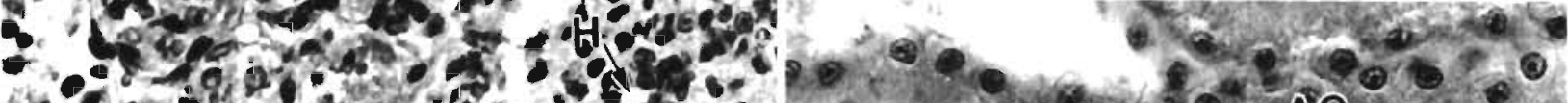

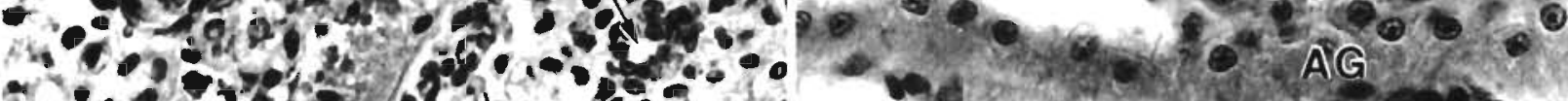

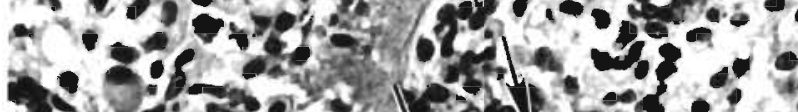

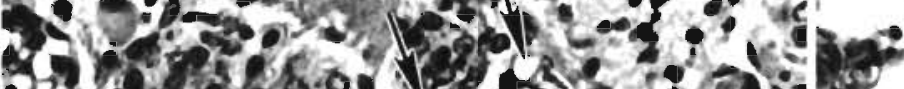
22.

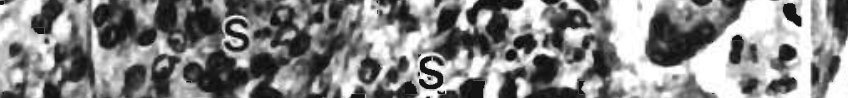

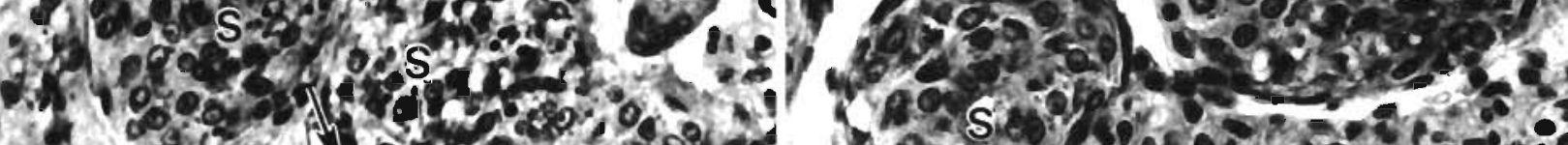

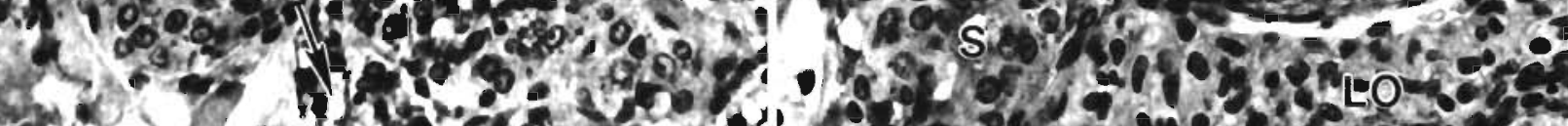

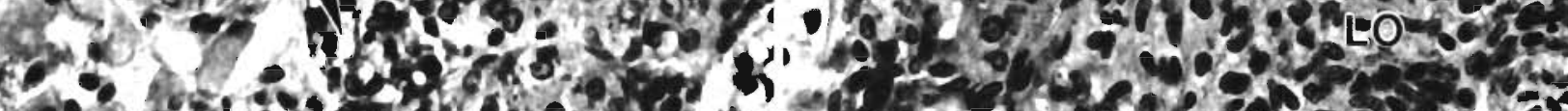
10.

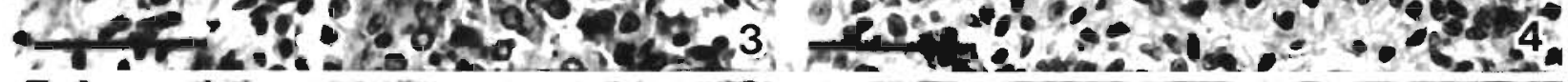

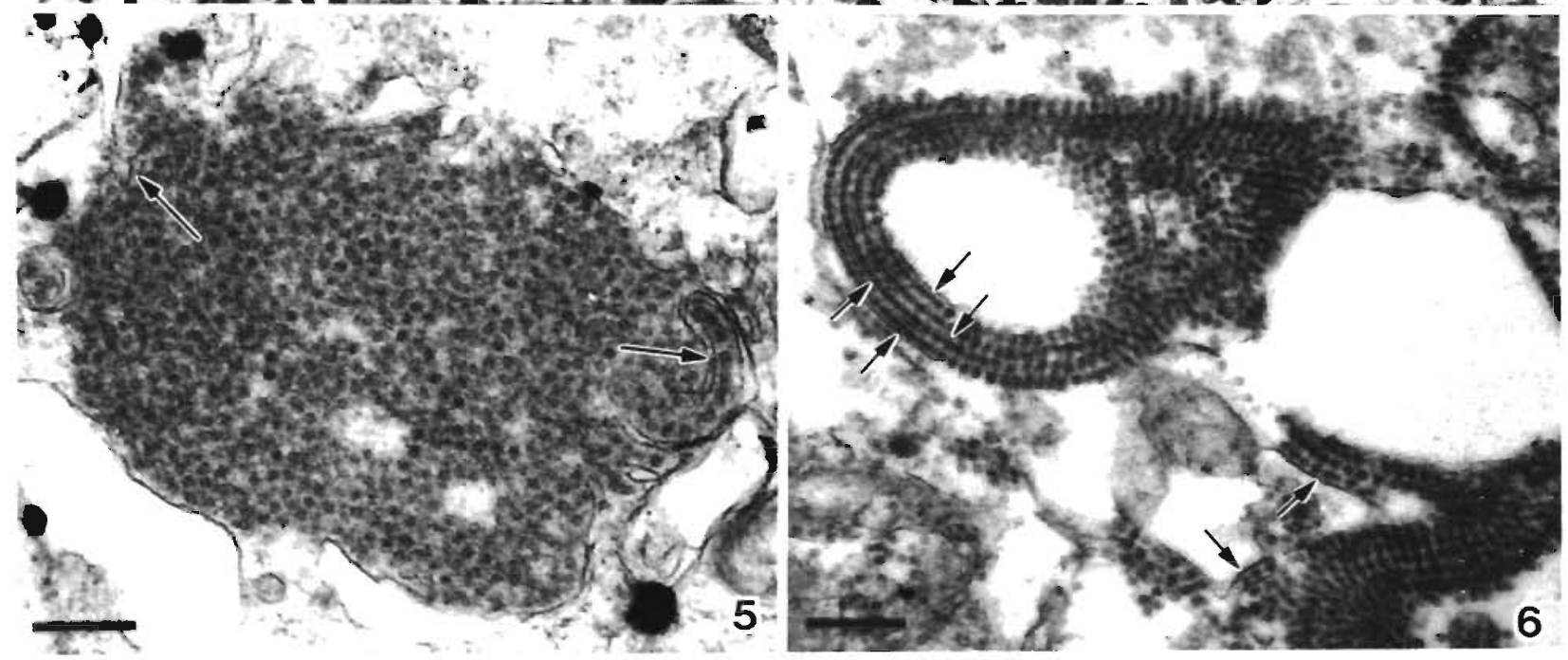


Following rapid thawing, the carapace was removed prior to homogenizing the cephalothoraces in TN buffer $\left(0.02 \mathrm{M}\right.$ Tris- $\left.\mathrm{HCl}_{1}, 0.4 \mathrm{M} \mathrm{NaCl}, \mathrm{pH} 7.4\right)$ using an Ultra-turrax tissue blender. The resultant suspension was clarified 3 times, at 2500, 6000 and $13000 \mathrm{rpm}$ (5534 rotor), in runs of 10,15 and $30 \mathrm{~min}$, respectively. The first peliet obtained was resuspended in TN buffer, re-homogenized, and centrifuged $10 \mathrm{~min}$ at $2500 \mathrm{rpm}$, the resulting supernatant fluid was pooled with the first supernatant fluid obtained previously, and the final supernatant fluid was pelleted $1.75 \mathrm{~h}$ at $220000 \mathrm{~g}$. The pellet obtained was then extracted 3 or 4 times in freon (1,1,2-trichloro-1,2,2-trifluoroethane). This freonextracted suspension was layered on a 15 to $40 \%$ $(\mathrm{w} / \mathrm{w}$ ) sucrose gradient and centrifuged at $110000 \mathrm{~g}$ for $3.75 \mathrm{~h}$.

Fractions containing presumptive virus particles were diluted in TN buffer and centrifuged at $285000 \mathrm{~g}$ for $1.75 \mathrm{~h}$. Pellets were resuspended and subsamples were placed on coated grids, negatively stained with $2 \%$ phosphotungstic acid (PTA) at pH 7.0, and evaluated for virus by TEM. Further purification of fractions containing virus was achieved on a preformed 15 to $45 \%$ (w/w) $\mathrm{CsCl}$ gradient in $1 \mathrm{mM}$ phosphate-buffered saline (PBS) ph 7.0 and run for $14.5 \mathrm{~h}$ at $200000 \mathrm{~g}$. Virus bands were collected with a Buchler Auto-densiflow coupled to a Pharmacia fraction collector, and the absorbance of each fraction was recorded using a Pharmacia UV monitor set at a wavelength of $254 \mathrm{~nm}$. Selected fractions were diluted in PBS buffer and pelleted at $285000 \mathrm{~g}$ for $2 \mathrm{~h}$ before being resuspended in a small volume of PBS for the subsequent analyses. Final preparations of purified virus were negatively stained and viewed by TEM as described previously.

Virus density. The density of purified virions was determined by refractive index measurement using an Abbe refractometer of each fraction collected from a 15 to $45 \%(\mathrm{w} / \mathrm{w}$ ) CsCl gradient (in $1 \mathrm{mM}$ PBS) after an isopycnic centrifugation at $200000 \mathrm{~g}$ for $15 \mathrm{~h}$, and the density values plotted on the absorbance record of the gradient.

SDS-PAGE. $12 \%$ polyacrylamide vertical gels were run using the Laemmli (1970) buffer system $(25 \mathrm{mM}$ Tris, 192 mM glycine, $\mathrm{pH}$ 8.3) containing $0.1 \%$ SDS. The run duration was $2 \mathrm{~h}$ at a constant current of 20 mA. Samples were diluted in gel sample buffer $(2 \%$ SDS, $5 \mathrm{M}$ urea, $1 \% 2$-mercaptoethanol, $15 \%$ glycerol, and $0.001 \%$ bromophenol blue) and heated to $100{ }^{\circ} \mathrm{C}$ for $3 \mathrm{~min}$ prior to loading of the samples onto the gel.
Molecular weight (MW) markers were bovine albumin, egg albumin and trypsinogen, which have MWs of 66 , 45 and $24 \mathrm{kDa}$, respectively. After washing in fixative solution, the gels were stained by the silver stain method of Morrissey (1981). The MW of the polypeptides was estimated by measurement of the electrophoretic mobilities according to the method of Weber \& Osborn (1969).

\section{RESULTS}

\section{Experimental animals - history}

The population of Penaeus vannamei reported here showed no signs of disease or other abnormalities during the 21 mo they were cultured in a closed recirculating seawater system on the University of Arizona campus. Their $1.5 \mathrm{~g}$ averagge weight at the termination of the 21 mo growout is small for this age and for shrimp of this species when grown under ideal conditions. However, this final size is not unusual for shrimp reared at high density (ca 500 individuals per 1500 l) in closed recirculating systems.

\section{Histopathology}

The principal lesions in the lymphoid organs of these shrimp were multifocal degenerative lesions of LO cords. Affected foci consisted of LO parenchymal cells that displayed more basophilic staining characteristics (than adjacent areas with normal LO cords) due to increased basophilia of the cytoplasm and to karyomegaly (Fig. 1). Affected LO cords often lacked a central hemolymph vessel (Figs. 1 \& 2), and in some cases formed 'spheroidal' structures composed of many cells (Figs. 3 \& 4). Some affected areas contained a few pyknotic nuclei, while other nuclei were hypertrophied and possessed marginated nuclear chromatin, which left the nucleolus within the central portion of an otherwise hypochromatic nucleus (Fig. 2). Many LO parenchymal cells contained cytoplasmic inclusion bodies that ranged from diffuse and eosinophilic to more discrete, basophilic, Feulgen positive, granular inclusions (Figs. 2 to 4). The size, location, and staining characteristics of these granules suggest that they may be either cell debris in phagosomes (with pyknotic or karyorrhectic nuclei) or virus inclusion bodies. Other

Figs. 7 \& 8. Fig. 7. TEM of membrane-associated $30 \mathrm{~nm}$ diameter LOVV nucleocapsids and LOVV virions (arrows) which have acquired their envelope from the host cell membrane. Scale bar $=100 \mathrm{~nm}$. Fig. 8. TEM of purified LOVV Illustrated are full (Fn) and empty ( $\mathrm{En}$ ) nucleocapsids showing a hexagonal profile; spherical enveloped virions (Ve); and markedly swollen enveloped virions, several of which have their central nucleocapsids exposed (Vs). Scale bar $=150 \mathrm{~nm}$ 

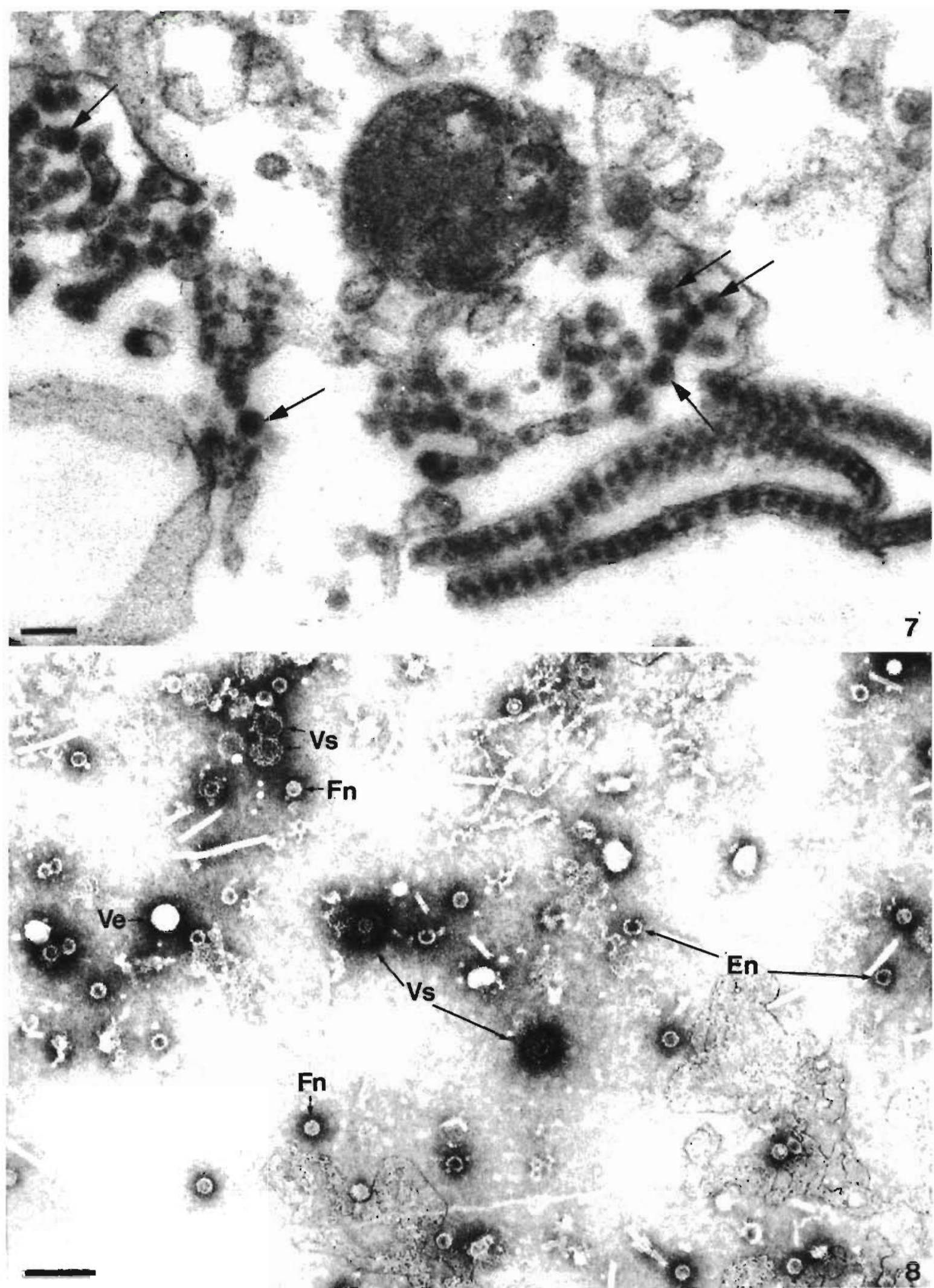
LO cells contained large, very prominent cytoplasmic vacuoles, some with basophilic bands of material closely associated with their membranes (Fig. 3). No significant host inflammatory response was noted within or adjacent to these LO lesions, and infiltrating hemocytes were typically not present in numbers greater than in normal LO tissue. No other lesions or abnormalities were noted in the shrimp examined.

\section{Ultrastructure}

Transmission electron microscopy of selected LOs from 3 shrimp showed all three to possess cytoplasmic masses of ca $30 \mathrm{~nm}$ diameter virus particles (Figs. 5 \& 6). The dense basophilic granular structures noted in histological preparations (Figs. 2 to 4 ) were found to be electron-dense structures that contained no virus-like particles (not shown). Cells containing virus particles were typically vacuolated. Virus particles trequently occurred in dense membrane-bound aggregations, and sometimes showed a tendency to form crystalline arrays (Fig. 5). The virus was also found to be frequently closely associated with membranes within the infected cells (Fig. 6). In such areas, enveloped particles (measuring 50 to $60 \mathrm{~nm}$ in diameter) were found, with the viral nucleocapsids apparently acquiring their envelope by budding or by the invagination and fusion of membranes of the endoplasmic reticulum or Golgi around individual nucleocapsids (Fig. 7)

\section{Isolation and purification of LOVV}

First attempts to purify the virus produced nonenveloped hexagonal full and empty particles of 30 to $32 \mathrm{~nm}$ diameter (Figs, 8 \& 9). However, subsequent purification attempts yielded virus preparations with 2 morphologically distinct particles: a 30 to $32 \mathrm{~nm}$ nonenveloped hexagonal particle and a spherical $50 \mathrm{~nm}$ diameter enveloped particle, which banded in $\mathrm{CsCl}$ gradients at 2 different densities. The same preparation exhibited possible evidence of a progression from one virus particle type to the other by the presence of particles showing different degrees of degradation of enveloped virions (Figs. 8, $10 \& 11$ ).

\section{Buoyant density of virus particles}

After isopycnic centrifugation in $\mathrm{CsCl}$ gradient, the larger enveloped particles banded at a density of 1.230 $\mathrm{g} \mathrm{ml}^{-1}$, while the smaller non-enveloped nucleocapsids banded at $1.320 \mathrm{~g} \mathrm{ml}^{-1}$

\section{Size and structure of LOVV}

The spherical enveloped particles, 52 to $54 \mathrm{~nm}$ in diameter, did not exhibit any peculiar structure, except small $7.5 \mathrm{~nm}$ subunits on the envelope surface (Fig. 10). The smaller hexagonal particles of $30 \mathrm{~nm}$ diameter exhibited 2 or 3 capsomeres on each edge of their icosahedral form, with 1 larger subunit at each of the vertices (Fig. 10). This subunit arrangement was most apparent on the vertices of empty particles (Figs. 8 to 10). The capsid, which was ca $4 \mathrm{~nm}$ thick, surrounded the inner area of ca 20 to $22 \mathrm{~nm}$ diameter.

Most interesting were degraded spherical particles, which showed the 6-sided nucleocapsid through a more or less swollen envelope. Such swollen particles reached a diameter of 65 to $68 \mathrm{~nm}$; on the largest swollen particles, the bilayered envelope seemed to consist of small spherical but empty subunits (Fig. 11). These virus-associated spherical subunits were also found free in the preparation and were interpreted as debris of degraded envelopes. Fig. 12 shows our interpretation of the structure of LOVV.

\section{Polypeptides of LOVV}

SDS-PAGE of the 2 different virus fractions showed that the nucleocapsid contains at least 2 polypeptides, with molecular weights of 37 and $38 \mathrm{kDa}$. The fractions containing enveloped particles and envelope debris show, in addition, at least a faint doublet at about 70 $\mathrm{kDa}$ and one other polypeptide of $60 \mathrm{kDa}$. In some preparations, 2 more additional bands (one of $45 \mathrm{kDa}$ and the other migrating with the dye, i.e. with a very low MW) were noted. These latter polypeptides are believed to be host cell contaminants rather than viral proteins.

Figs. 9 to 12. Fig. 9. High-magnification TEM of full (Fn) and empty (En) ca $30 \mathrm{~nm}$ diameter nucleocapsids of LOVV A few particles show especially well the arrangement of capsomeres on their surfaces (arrows). Others show the presence of a large capsomere at each vertex (arrowheads) of the icosahedron, interspersed with 2 or 3 smaller subunits composing each face of the capsid. Scale bar $=25 \mathrm{~nm}$. Fig. 10. High-magnification TEM of an enveloped LOVV particle (Ve) showing the regularly arranged $7.5 \mathrm{~nm}$ diameter suburits projecting from the envelope surface (arrows). Also shown is an empty particle (En) that shows the presence of 2 or 3 capsomeres on each edge of the particle with larger subunits (arrowheads) visible at some of the vertices. Scale bar $=25 \mathrm{~nm}$. Fig. 11. Enlargement of a swollen and degrading LOVV virion. Subunits of the envelope are apparent (E), as is the now exposed nucleocapsid (N). Scale bar $=25 \mathrm{~nm}$. Fig. 12. A graphical representation of the structure of LOVV, showing the inner $30 \mathrm{~nm}$ diameter icosahedral nucleocapsid within the enveloped $60 \mathrm{~nm}$ diameter mature virion 


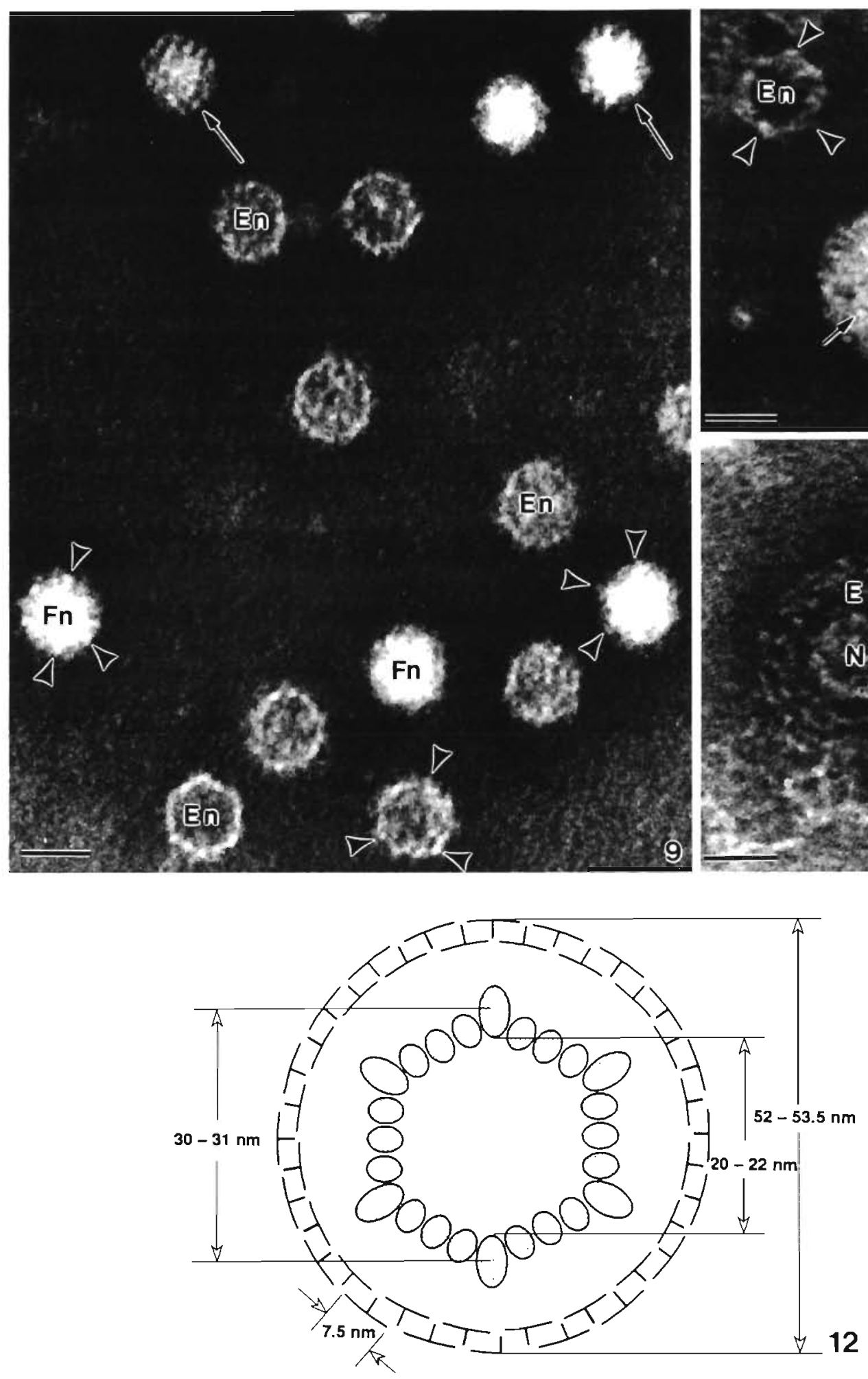




\section{DISCUSSION AND CONCLUSION}

Based on its size, shape, structure and virogenesis, LOVV can be related only to the Togaviridae family (Matthews 1982). Indeed, this agent develops in cytoplasm, where icosahedral nucleocapsids accumulate before they acquire the host-cell-derived envelope of the mature virion

Because so little virus-infected material was available in this study, attempts to extract and characterize nucleic acid of LOVV were unsuccessful. However, because no Feulgen-positive reaction (for DNA) associated with cytoplasmic virus aggregates was detected in histological sections of LOVV-associated LO lesions, we presume that the virus contains RNA. Moreover, the density values and the polypeptide analysis are in general agreement with the characteristics of the Togaviridae (Matthews 1982). Hence, the discovery of LOVV in Penaeus vannamei appears to be the first report of a togavirus in any marine invertebrate animal.

Despite the presence of detectable histopathology only in the lymphoid organs of the affected Penaeus vannamei, our successful attempts to purify the virus from the other areas of the cephalothorax indicate the agent is present in other cephalothoracic tissues, where it apparently produces much more subtle histological changes. In the present study TEM examinations were limited to lymphoid organs, and hence no evidence of the presence of LOVV in other tissues was obtained.

For the moment, nothing is known about the prevalence and pathogenicity of this virus in wild or cultured penaeid shrimp populations. However, the remarkable similarity of histological changes noted in the lymphoid organs of Penaeus monodon (Lightner et al. 1987, Brock \& Lightner 1990, Owens et al. 1991) suggests that LOVV (or a related agent) may occur as a common, if not significant, pathogen in Asian and Australian penaeids. If this hypothesis is later found to be the case, it may be possible to purify more of the virus from Asian- and Australian-derived penaeid shrimp with lymphoid organ lesions and subsequently to complete characterization of this newly recognized type of virus in penaeid shrimp.

Acknowledgements. This study was funded in part by the U.S Department of Agriculture through grant number CSRS 88-

Responsible Subject Editor: J. E. Stewart, Dartmouth, N.S., Canada
38808-3320. Also acknowledged is the assistance by Tom Bell (Univ. of Arizona) in preparing the computer-generated image of LOVV used as Fig. 12.

\section{LITERATURE CITED}

Bell, T. A., Lightner, D. V (1988). A handbook of normal Penaeid shrimp histology. World Aquaculture Society, Baton Rouge

Brock, J. A., Lightner, D. V. (1990). Diseases of Crustacea, Chap. 3.1, Diseases caused by microorganisms. In: Kinne, O. (ed.) Diseases of marine animals, Vol. III, Cephalopoda to Urocordata. Biologische Anstalt Helgoland, Hamburg. p. 245-349

Humason, G. L. (1979). Animal tissue technique, 4th edn. Freeman, San Francisco

Laemmli, U. K. (1970). Cleavage of structural proteins during the assembly of the head of bacteriophage T4 Nature, Lond. 227: 680-685

Lightner, D. V., Brock, J. A. (1986). Proliferative changes of glandular and lymphoid tissues of the penaeid shrimps Penaeus monodon and $p$. vannamei (Crustacea: Decapoda) that possess characteristics of adenocarcinomas and lymphosarcomas. In: Samson, R. A., Vlak, J. M., Peters, D. (eds.) Fundamental and applied aspects of invertebrate pathology. Foundation of the Fourth International Colloquium of Invertebrate Pathology, Wageningen, p. 469

Lightner, D. V., Hedrick, R. P., Fryer, J. L., Chen, S. N., Liao, I. C., Kou, G. H. (1987). A survey of cultured Penaeid shrimp in Taiwan for viral and other important diseases. Fish Path. 22: 127-140

Matthews, R. E. F. (1982). Classification and nomenclature of viruses. Intervirology 17: 1-199

Morrissey, J. H. (1981). Silver stain for proteins in polyacrylamide gels: a modified procedure with enhanced uniform sensitivity. Analyt. Biochem. 117: 307-310

Owens, L., De Beer, S., Smith, J. (1991). Lymphoidal parvolike virus in Australian prawns. Dis. aquat. Org. 11: 129-134

Owens, L., Hall-Mendelin, S. (1988). Australian tropical penaeid diseases of importance to mariculture. In: Perkins, F. O., Cheng, $T$ C. (eds.) Abstracts of 3rd international colloquium on pathology in marine aquaculture. Virginia Institute of Marine Science, Gloucester Point, VA, p. 161

Paynter, J. L., Lightner, D. V., Lester, R. J. G. (1985). Prawn virus from juvenile Penaeus esculentus. In: Rothlisberg, P. C., Hill, B. J., Staples, D. J. (eds.) Second Australian national prawn seminar. National Prawn Seminar 2, Cleveland, Australia, p. 61-64

Weber, K., Osborn, M. (1969). The reliability of molecular weight determination by dodecyl sulfate-polyacrylamide gel electrophoresis. J. biol. Chem. 244: 4406-4412

Manuscript first received: April 16, 1992

Revised version accepted: June 30, 1992 